

\section{Sindicatos y Responsabilidad Social Empresarial (RSE) en el posconflicto colombiano: ¿una oportunidad para el diálogo social? ${ }^{1}$}

Por Edgar Augusto Valero ${ }^{2}$

\section{Introducción}

L

a reestructuración empresarial y los cambios relacionados con la internacionalización de la economía colombiana en las últimas décadas han debilitado un ya estrecho campo de negociación colectiva y de derechos laborales. En este contexto, de cara a certificar sus procesos y proyectarse al mercado externo, se han producido cambios en la estrategia corporativa de las firmas, cambios perceptibles en nuevos discursos de legitimación que ahora se apoyan en diferentes esquemas de Responsabilidad Social Empresarial (RSE). Este conocido recurso corporativo es usual y propio de las dinámicas de globalización en contextos desregulados en los que los directivos desean cultivar una imagen favorable y prevenir procesos potencialmente adversos al plan estratégico.

Artículo recibido en septiembre de 2016

Artículo aprobado en noviembre de 2016

2 Magíster en sociología y PHD en historia, está vinculado al Departamento de Sociología de la Universidad Nacional de Colombia. 
En los planes de acción de la RSE, como diseño de políticas corporativas que son, se nos revela una lógica de lo típicamente unilateral, voluntario y discrecional que, desde luego, tiene especificidades para los diferentes territorios y espacios económicos nacionales. Las firmas adhieren a principios y metodologías de alcance internacional como base para formular objetivos y acciones en lo ambiental, económico y social, de modo que uno de sus capítulos se ocupa del ámbito interno de las relaciones laborales. Es así como en la presentación de los informes de RSE se expone una serie de autocompromisos y adhesiones voluntarias a principios éticos de equidad y respeto por los derechos de los trabajadores.

El medio colombiano se ha caracterizado por una de las más bajas tasas de afiliación sindical, una muy restrictiva legislación sobre negociación colectiva y una cultura empresarial adversa a la acción reivindicativa de los trabajadores. Lo anterior en relación con un sistema político relativamente excluyente y vertical, con pocos canales para la concertación, y en medio de un prolongado conflicto armado explica que, a diferencia de otras sociedades, poco se haya tomado en cuenta a quienes en esas conceptualizaciones se llamarían un grupo de interés interno (Mitchel, Agle y Wood 1997; Partridge Katharine 2006), y apenas comienzan a ser valoradas las prácticas de RSE como una posibilidad de diálogo constructivo y mejora de la situación laboral.

En este artículo se analizarán las tendencias que muestran los programas de RSE respecto a los derechos laborales y la negociación colectiva, para explorar además la posibilidad de que, en la llamada etapa de posconflicto que comienza, las organizaciones sindicales se aproximen a estos espacios y aprovechen algunas de las posibilidades de debate y contrastación de estos discursos gerenciales que se proyectan insistentemente a la sociedad, pero hasta ahora no han tenido ningún tipo de interlocutor.

Se describirán procesos representativos en relación con el manejo laboral, a partir de la explicación de factores determinantes de la esfera 
empresarial y socio-laboral. Se acudirá a fuentes variadas, entre otras, la consulta de informes de sostenibilidad de las empresas, debidamente contrastada con información de organismos sindicales y de relaciones laborales.

\section{La RSE como faceta de la globalización neoliberal y tema de la ciencia social}

En un momento en que resulta más abrumador el poder del capital y las corporaciones continúan debilitándose en todas las sociedades antiguos mecanismos de regulación de las interacciones capital-trabajo, como los de las relaciones industriales y la negociación colectiva que situaban la remuneración y las condiciones de trabajo en la esfera de los acuerdos políticos como temas sujetos a institucionalización e intervención estatal.

En todos los contextos nacionales, el signo de la época parece ser que los empleos estables y sujetos a protecciones sufren el embate de las dinámicas de descolectivización de las relaciones laborales y el debilitamiento de las funciones integradoras del trabajo (Castel, 2010). Cada vez en mayor medida la calidad de los empleos se deteriora y los nuevos referentes de la situación ocupacional son las capacidades negociadoras individuales y ciertas políticas y estrategias específicas de las firmas.

La probabilidad de que se revierta la espiral de deterioro en la calidad de los empleos, en ciertos contextos empresariales, ya no parece ligada a los mecanismos institucionales de regulación del trabajo o a las posibilidades de acuerdo social y negociación, que siempre han sido reducidas, sino más bien a una variada gama de nuevas orientaciones y programas, en torno a los cuales las firmas voluntaria y unilateralmente promueven cambios.

En primer término, se trata de un ámbito permeado por nuevos elementos de cultura corporativa sustentadora de la hegemonía por vía 
de directivos cuya formación está centrada en enfoques sicologistas de motivación y liderazgo que pretenden el consenso desde lo individual, sin reconocer los aspectos conflictivos plurales inherentes a las relaciones de trabajo bajo el capitalismo (Rossi, 2016). Dentro de ese contexto encontramos una variedad de nuevos esquemas organizativos como los del enfoque felicista (Greenberg, Hemingway, 2007), el emprenderismo y el coaching ${ }^{3}$.

Dentro de estos nuevos recursos corporativos de organización, cuya aplicación tiene consecuencias para las relaciones laborales, se destacan por su continuidad y extensión los discursos y prácticas de RSE. A lo largo de las últimas décadas han sido parte esencial del proceso de globalización económica y mundialización del comercio. Su surgimiento está relacionado con publicitados hechos de abuso y afectación contra el medio ambiente, los trabajadores, comunidades y consumidores, que llevaron a organismos internacionales como la ONU, OIT, OCDE, ONG y grandes corporaciones a plantear la necesidad de una autorregulación o re-regulación de varios aspectos de la actividad económica y el manejo laboral.

Aunque algunos autores sitúan su origen en el comienzo mismo del capitalismo ${ }^{4}$, su auge ocurre en un período reciente en que las dinámicas de cambio y desregulación de inspiración neoliberal han erosionado en casi todas las latitudes - mecanismos estatales y públicos de control

t Modelo de organización del trabajo y autoridad centrado en la actuación de un líder que, con su conocimiento de los subordinados y capacidad de motivación a su equipo, asegura el cumplimiento de las metas y también el desarrollo personal y profesional de cada uno de ellos; lo anterior dependiendo del buen ajuste que tengan al esquema de actuación seguido y su nivel de logro individual.

4 El esquema evolutivo sugerido por Patrick Murphy (2007) describe una lenta conformación de la perspectiva de la RSE, partiendo de un período precursor que se extiende desde el comienzo mismo del capitalismo hasta 1900; luego una fase filantrópica hasta 1950: en ambas la caridad, paternalismo e idea de servicio son esenciales. De acuerdo a esta periodización, que se considera un referente amplio 
sobre la actividad económica y han desarticulado en diferente grado los avances en instituciones de salvaguarda colectiva como la normatividad laboral y los sistemas de protección social.

Para un buen número de divulgadores y analistas, el posicionamiento del tema en la vida empresarial ha estado relacionado con importantes desastres del mundo financiero que minan la confianza corporativa, al tiempo que por catástrofes ambientales y grandes escándalos mediáticos relativos a la arbitrariedad laboral. Igualmente, las grandes corporaciones, en especial en el primer mundo, experimentan presiones y cuestionamientos de la opinión pública en relación con la afectación ambiental, laboral y social que sus actividades ocasionan. Los riesgos de deterioro reputacional, el perjuicio a la imagen corporativa, los boicots de consumidores y de organizaciones no gubernamentales, e incluso caída del precio de las acciones, hacen parte de un conjunto de incertidumbres y dificultades que la gestión debe prevenir.

Desde los años noventa, se ha recorrido un largo camino en materia de diseño de principios, instrumentos e indicadores de RSE, desde el lanzamiento del Global Compact de Naciones Unidas en 1999 y la firma de los Objetivos de Desarrollo del Milenio un año después; pasando por la divulgación del Libro Verde y la generación de la norma ISO 26000 y las metodologías estandarizadas del Global Reporting Initiative GRI (Raufett, 2012).

De acuerdo con el tipo de negocio y mercado en el que se desempeñe una compañía, puede adoptar las herramientas más convenientes para mostrar que controla sus procesos y, de ese modo, construir una imagen pública. Un ejemplo está en el sector floricultor colombiano que, con su

más que un tránsito necesario y gradual de las firmas, en la segunda mitad del siglo XX se vivieron fases de toma de conciencia, confrontación de problemas, reconocimiento y compromiso. 
gran presencia en mercados extranjeros, tuvo que anticiparse a barreras y boicots por motivos ambientales y sociales, a través de la creación del código de conducta Florverde, que más adelante se convirtió en un sistema de certificación avalado por un organismo independiente (Valero y Camacho 2006; Asocolflores 2009). Para otras firmas, un papel similar cumplen declaraciones de principios éticos, compromisos de buena ciudadanía corporativa, normas ISO, definición de grupos de interés, informes de sostenibilidad, entre otros.

El tema de la RSE ha sido abordado por estudiosos en áreas de economía, empresa, estrategia, organización, ética y ciencias sociales (Alvarado, Bigné, Currás, 2011). La sociología ha explorado variadas temáticas: desde los más amplios sobre el sentido de esta tendencia empresarial en el capitalismo actual, hasta los más específicos relacionados con cuestiones ambientales, comunidades y grupos sociales particulares. Algunos trabajos destacados muestran la diversidad de las cuestiones analizadas: Lazin (2007) estudia los procesos que condujeron de las prácticas caritativas a la conformación de la filantropía corporativa de las grandes fundaciones del capitalismo americano que, al comienzo del siglo XX, surgieron con con Rockefeller y más tarde continuaron con Soros; para ello describe sus programas en países no desarrollados, las interacciones con los avances de la revolución verde y se interroga sobre su verdadera efectividad.

El análisis de Boeddeling (2012) sitúa el tema de la RSE como un planteamiento sobre el papel que debe cumplir la economía en la sociedad y valora las posibilidades de la sociología económica weberiana en la exploración de los diferentes sentidos y orientaciones que a nivel de sus promotores tiene la acción social, los complejos nexos con las instituciones y la racionalización de la acción económica. En este sentido, más allá de las orientaciones puramente pragmáticas e instrumentales compartidas por todos los actores de las organizaciones, admite la existencia de conflictos de valor entre los partícipes de la acción en torno a intereses materiales e ideales en los cursos de acción que genera la RSE 
y la posibilidad de que esta encarne una nueva ética de la acción económica, y una específica base de legitimidad para la firma. La cuestión central en este autor es que los intereses ideales tienen una significación que supera la orientación instrumental o normativa, y que la RSE puede ser entendida como racionalidad con arreglo a valores.

Desde una perspectiva contrastante con la anterior, pero tal vez representativa de un gran número de interpretaciones de la RSE, en una tesis de ciencias sociales se realiza un ejercicio analítico de inspiración marxista (Karaca, 2012). En este caso se caracteriza la ética de la RSE como un discurso cómodo, estrechamente ligado a las circunstancias del mercado y el interés de acumulación. La RSE representa un fenómeno global de humanitarismo-espectáculo típico de la era neoliberal, un esfuerzo legitimador de la ideología capitalista, una manera de naturalizar impactos aún no explicados, una pretendida solución a problemas ambientales y humanos que no toca la causa esencial de los mismos, que es el capitalismo mismo.

Dentro de la corriente de los Critical management studies, Bobby Banerjee (2011) expresa un fuerte escepticismo por los contenidos de estrecho interés capitalista y legitimador del poder corporativo implícitos en los discursos de RSE, ciudadanía corporativa y sostenibilidad. Reconoce el valor que hay en el fondo de estos planteamientos, pero señala que los diversos problemas relacionados con el poder corporativo deben salir del estrecho y sesgado interés empresarial y ser abordados por el conjunto de la sociedad, lo cual requiere un examen crítico de la racionalidad que preside la economía, de la forma como participan las partes interesadas y de la dinámica de las relaciones entre las empresas, las ONG, los gobiernos, la comunidad, los grupos y los organismos de financiación. El nuevo colonialismo corporativo, oculto tras los discursos de RSE, impone a la sociedad formas de participar en la economía, mientras que ignora las consecuencias de la toma de decisiones de gestión y no se construyen efectivas formas de rendición de cuentas y resolución de conflictos. 
En el campo específico del trabajo y las relaciones laborales, el análisis de Rainer Dombois (2011) sobre multinacionales señala del mismo modo el carácter predominantemente voluntarista de las nuevas modalidades de regulación y su trasfondo de autocompromisos frente al entorno y al medio ambiente, principalmente en lo relacionado con los trabajadores y sus representantes; destaca que el referente esencial no son las normas legales, sino más bien las expectativas sociales.

El autor deja claro que décadas atrás las directrices de comportamiento de los consorcios transnacionales se cimentaban en una obligatoriedad derivada de compromisos interestatales y, por ello, eran códigos públicos, pero desde los años noventa el escenario es tomado gradualmente por los arreglos privados, basados en los autocompromisos voluntarios de las empresas.

Del mismo modo, expresa escepticismo acerca de que los autocompromisos de las empresas transnacionales sustituyan modalidades nacionales e internacionales de regulación del trabajo, y considera que siguen siendo necesarios:

acuerdos institucionales internacionales que comprometan a los Estados, o que estén en la posibilidad de obligar el cumplimiento de los principios y estándares en los sistemas ocupacionales como la OIT, acuerdos regiona les, supraestatales o propuestas inter-estatales, tales como la política social internacional de la Unión Europea o el Acuerdo Norteamericano de Cooperación Laboral (Dombois, 2011, p. 270).

La actuación y el poder de las firmas multinacionales, dentro y fuera de sus países sede, ha sido un importante campo de acciones y estudios de RSE. Como veremos, se encuentran también las más dinámicas e innovadoras posturas y acciones de sindicatos y ONG interesadas; se trata de procesos de interés sociológico e indudable valor para la comprensión de las dinámicas capitalistas globales en ámbitos nacionales. 
El propósito de rescatar la imagen corporativa en la atmosfera de críticas y escándalos de la última década ha estado presente en un gran número de planes de RSE que generan acciones de tipo voluntario, unilateral y autoregulado por parte de las compañías, sin llegar a tener un ámbito de aplicación global en todos los países en los que operan (Vidal, 2010).

Consecuencia de lo anterior, es que los códigos que de este modo comprometen a las organizaciones no son exigibles por ningún medio legal, por lo que queda excluida la responsabilidad jurídica por incumplimiento de los mismos. Se trata de una típica despolitización y desregulación de las reglas que rigen el funcionamiento de las firmas en la actualidad. Además, el discurso sobre ética de los negocios del que surgen tales modelos de acción y su carácter discrecional los acerca mucho a un sentido paternalista.

\section{Irrupción sindical en la RSE: oportunidades y avances}

Recientes procesos muestran que en torno a la aplicación de la RSE se ha conformado un dinámico campo de luchas y relaciones de fuerza entre compañías y actores sociales como los sindicatos. Estos avanzan en planes de acción nacionales e internacionales que contrarresten las estrategias de las corporaciones multinacionales para ocultar sus impactos negativos con recursos publicitarios, y para desplazar las exigencias legales y de negociación colectiva a los terrenos voluntarios y discrecionales de la RSE.

Frente a ello, las organizaciones de trabajadores se esfuerzan por convertir los autocompromisos y códigos éticos unilaterales de las firmas en acuerdos marco- internacionales de mayor alcance, suscritos con las federaciones sectoriales internacionales, para así avanzar en lo que sería una forma de negociación colectiva transnacional y una globalización del movimiento sindical (Vidal, 2012). 
Es interesante señalar que en diferentes espacios internacionales los sindicatos han superado las iniciales etapas de desinformación, indiferencia o rechazo ante los programas corporativos de RSE, y de modo creciente se plantean conocer a fondo conceptos y metodologías como grupos de interés, RSE estratégica, norma ISO 26000, Modelo GRI (Global Reporting Initiative), para participar de los programas con argumentos y propuestas ante las firmas. En este caso, se aplicaría la idea de James Scott (1990, p.80) respecto a que exigir a los grupos dominantes que se comporten de acuerdo con la presentación idealizada que han hecho de sí mismos es una posibilidad en el repertorio de las formas de lucha.

Una de las más conocidas experiencias fue la que condujo en mayo de 2013, a la firma de un acuerdo entre más de doscientas marcas globales y federaciones sindicales internacionales de industria y servicios, entre ellas IndustriALL Global Union y UNI. De acuerdo con el documento que describe el caso, se logró

un nuevo marco que suponía pasar de la iniciativa unilateral en los compromisos y prácticas empresariales de Responsabilidad Social (muchas de ellas todavía simple marketing empresarial) a iniciativas colectivas consensuadas con uno de los principales "grupos de interés", el sindicalismo organizado, que en este caso era el sindicalismo "global” (Boix, 2015, p. 2).

Los impactos mediáticos de varias tragedias con víctimas de los derrumbes de plantas subcontratistas en países asiáticos crearon un ambiente favorable a tales avances. De modo que, dos años después de ese inicial logro en relación con la seguridad en el trabajo y el derecho a la vida, se aborda una dimensión más amplia del salario digno, decente, vital, como derecho colectivo alcanzable en la negociación colectiva.

Este proceso de intervención sindical se convirtió en una efectiva negociación colectiva, nacional y supranacional, que comenzó en Camboya y Bangladesh, pero después se extendió a países de todos los continentes y, al mismo tiempo, obligó a que se pasara de los compromisos 
unilaterales a los compromisos pactados e hizo realidad los Acuerdos Marco Globales. Lo anterior a partir de compromisos de responsabilidad social, que por vía de códigos de conducta o adhesiones a códigos globales habían hecho las firmas.

Estos acuerdos, que comprometieron en primera instancia a la firma española Inditex, eran propuestos desde 2002 y se proyectaron de modo que contemplan el ámbito sectorial y territorial; pretenden una eficaz implicación a lo largo de toda la cadena de valor y permiten pasar de los compromisos empresariales unilaterales hacia otros consensuados. Derivado de esta experiencia queda un claro planteamiento para los sindicatos en el sentido de aprovechar las posibilidades de la RSE:

Cuando más de la mitad de la clase trabajadora mundial opera en las cadenas de valor de las empresas multinacionales, transnacionales, cuando los Convenios de la OIT tienen un gran valor de referencia pero escaso de directa eficacia, cuando las violaciones de los más elementales derechos del trabajo se producen a lo largo y ancho de nuestro mundo globalizado, la Responsabilidad Social empresarial ha demostrado que puede ser un útil instrumento para progresar hacia la dignidad del trabajo. Con una condición esencial: la intervención de los grupos de interés, del de los trabajadores, el sindical, en particular. Y para la eficacia de esta intervención hay que avanzar desde los compromisos empresariales unilaterales a la contractualización de su contenido y sobre todo de su aplicación, en primer lugar con el sindicalismo organizado (Boix, 2015, p.14).

Otras organizaciones muestran su decidida intención de aproximarse a los mecanismos de RSE y hacerlos conocer entre sus afilados, con la intención de trascender los propósitos de imagen corporativa y marketing de las gerencias y convertirlos en un camino hacia la participación y la recuperación de la calidad de los derechos laborales y la calidad de los empleos. En el caso de las Comisiones Obreras de Castilla-La Mancha, después de varios años de experiencias, se propone una combinación 
de "vigilancia, diálogo, presión y negociación con las empresas"; comités de empresa para controlar el cumplimiento de las declaraciones unilaterales de RSE, para exigir y verificar su real aplicación práctica y para hacer denuncias si es del caso (Jiménez, 2007).

Dentro de una lógica de dar tratamiento diferente para cada esquema que empleen las empresas sugieren variadas estrategias, como la redacción de contramemorias que creen polémica alrededor de supuestos buenos resultados que se divulgan; además de conocer las normas o instituciones internacionales a las que las empresas se vinculan voluntariamente para extender el seguimiento crítico. Los compromisos unilaterales con el seguimiento público pueden hacerse de cumplimiento exigible para después pasar a la verificación y más adelante a la exigencia de medidas correctoras de los incumplimientos. Del mismo modo que, en el caso de Industrial, se propone la redacción de acuerdos marco-sectoriales para la inspección de las operaciones de las multinacionales en todos los países donde tengan actividades.

El manual de Comisiones Obreras de Castilla-La Mancha, destaca también cuestiones de más amplitud como las del desarrollo socialmente sostenible, políticas frente a las empresas transnacionales y la promoción del desarrollo regional. Convocan a las principales confederaciones a evitar sus típicos temores a perder protagonismo y aprovechar las posibilidades de la RSE, vinculando sus esfuerzos con ONG y otros sectores y organismos sociales que podían ser aliados; participar en foros multilaterales y debates sobre la globalización.

En el caso de la española Unión sindical Obrera USO, se define la RSE como parte de los actuales cambios del mundo globalizado, y como parte de la necesidad de informarse sobre sus mecanismos para beneficiarse de ella e incluirla en sus plataformas de negociación y en su relación con la empresa, de cara a aportar propuestas y resolver problemas en el contexto de crisis económica actual. A este respecto es importante la exigencia de aplicar criterios sostenibles de producción, 
medidas de conciliación, igualdad de oportunidades y mejora en prevención y salud laboral (USO 2010).

Se asume la RSE como un nuevo paradigma de comportamiento empresarial, a partir del cual se puede generar diálogo y cooperación en el ámbito nacional e internacional, entre empresas, sindicatos, organismos públicos, empleados, asociaciones, ciudadanía, de modo que los sindicatos sean los interlocutores válidos de la RSE.

En el mismo sentido está la postura de la European Trade Unión Confederation, pues plantea que, a pesar de sus debilidades, la RSE ofrece buenas oportunidades a los sindicatos en cuanto al diálogo social continuo, la transparencia y la generación de nuevas estrategias en la Unión Europea (Ormond, 2014).

Defienden también que los mecanismos de las relaciones laborales y la negociación colectiva no deben ser sustituidos por las instancias voluntarias de la RSE, sino que estas deben ayudar a que se cumplan las responsabilidades legales. Debe permitirse a los trabajadores participar en el diseño de la RSE, e igualmente organizaciones sindicales nacionales e internacionales deben conformar una red para hacer que la RSE se cumpla a lo largo de toda la cadena productiva, pues los trabajadores no son una parte interesada solamente en hacer consultas e informes, sino que debe ser un ente con potestad en la negociación colectiva y debe actuar como instancia de supervisión de la RSE.

En este caso, la proyección de los sindicatos hacia la RSE toma en cuenta directrices muy conocidas, aunque muchas de ellas no sean vinculantes, precisas y exigibles legalmente, como las de OCDE, norma ISO 26000, principios del Pacto Mundial de las Naciones Unidas, Declaración tripartita de la OIT de principios sobre las empresas multinacionales y la política social. En ese orden de ideas, los sindicatos deben promover que los informes de RSE consulten fuentes sindicales, aborden la cadena productiva en toda su extensión, empleen adecuados 
indicadores de análisis y valoración, incluyan asuntos relevantes con información precisa, no falten a la verdad y aborden aspectos problemáticos e impactos negativos.

En el contexto latinoamericano se registran algunas evidencias de similar orientación y posicionamiento sindical estratégico ante la RSE como recurso empresarial de la globalización neoliberal ${ }^{5}$. Un manual mexicano propone aprovechar la idea de trabajo multi-stakeholder, que subyace a la ISO 26000 y los elementos participativos y de representación plural que estuvieron presentes en su diseño, además del amplio alcance de sus formulaciones dirigidas no solo a la empresa privada, sino a la sociedad en general y a todas sus organizaciones (Veloz, 2008).

Por lo anterior, se espera que asuntos transversales de gran calado para México como el de los derechos humanos sean mejor resueltos con base en este instrumento; igualmente se espera que los sindicatos debidamente ilustrados sobre sus contenidos y motivados al diálogo consigan un mayor respeto a los derechos laborales. Sobre estos aportes, grupos de interés como las organizaciones de la sociedad civil, los sindicatos y las organizaciones de consumidores pueden negociar propuestas con sectores como la industria.

En la misma dirección, se considera posible que las organizaciones de la sociedad civil se esfuercen por crear un marco regulatorio internacional de la RSE que sea vinculante: “El propósito es superar las lógicas de voluntariedad y unilateralidad que se expresan en la autorregulación, es decir, en la implantación de sistemas privados de regulación y certificación, versus la imposición de obligaciones desde el derecho” (Veloz, 2008 p.17).

Ver para Perú: Fernández M., (2010) y para Chile: Cerda Becker C., y Cuevas Valenzuela H., (2014) 


\section{RSE en Colombia: presencia y auge actual}

Dentro de las firmas nacionales más grandes y modernas, del mismo modo que las de inversión extranjera, desde hace varias décadas se ha extendido la aplicación de programas de RSE, de forma que es posible construir una periodización de estas prácticas, partiendo de los elementales planteamientos y acciones benéficas en la primera mitad del siglo $\mathrm{XX}$; que luego continua con una profesionalización de la asistencia en las llamadas empresas providencia y llega a épocas recientes. Con los cambios de la globalidad neoliberal y el influjo del Acuerdo global de la ONU de 1999, se hacen más diversos los discursos y metodologías: balance social, grupos de interés, ciudadanía corporativa, marketing responsable, reportes de sostenibilidad GRI (Rauffet y Barrera, 2010).

En la etapa más reciente, a instancias de organizaciones especializadas, consultores y universidades se ha intensificado la difusión del discurso de la RSE a diferentes sectores de la vida nacional. En los medios masivos de comunicación se percibe una sofisticación de estrategias publicitarias alrededor de programas y realizaciones, que a veces parece sobredimensionada respecto a las acciones concretas desarrolladas. El trasfondo de estos discursos es variado, oscila entre el voluntarismo ético y la idea pragmática de que las acciones de RSE convertidas en "beneficio reputacional” son un factor estratégico en la lucha por el mercado y la rentabilidad.

Un escenario muy destacado en la difusión de las prácticas de RSE surge de la reciente "reprimarización" de la economía con notable inversión extranjera; lo que pone en auge a sectores mineros y extractivos de poca generación de empleo que, con sofisticadas estructuras técnicas y empresariales, actúan en zonas atrasadas del país. De modo que el resultado y proyección de la RSE a la sociedad dependerá de la naturaleza del empresariado y sus estilos de gestión en el escenario competitivo que sortea en el presente, tanto como de antecedentes históricos y características del contexto. 
En los últimos años, la firma de tratados de libre comercio se convierte en un factor determinante de las estrategias de RSE. En un principio se apreció la posibilidad de mejoras parciales en las relaciones laborales, condiciones de trabajo y de negociación colectiva ligadas a las exigencias externas, norteamericanas y europeas, implícitas en condiciones de los TLC; del mismo modo, hay expectativa por los probables cambios derivados de decisiones, como la del actual Gobierno respecto al ingreso de Colombia a la OCDE.

Sin embargo, tales cambios han sido más formales y aparentes que reales; de modo que, por lo fragmentarios y leves, suscitan el escepticismo y la crítica de las organizaciones de trabajadores ${ }^{6}$, tanto en la esfera institucional como en la empresarial privada. Señalan que se ha vuelto a establecer el Ministerio de Trabajo, pero con tal debilidad institucional y demostrada incapacidad de vigilancia y control, que no puede promover mejoras apreciables en el respeto a los derechos laborales. En el mismo sentido se valora la prohibición a las firmas de emplear Cooperativas de trabajo asociado CTA (Ley 1429 de 2010), la más nociva y extendida de las modalidades de tercerización aplicadas, ante la que el empresariado, con su conocida recursividad, intensificó otros esquemas como el de la contratación sindical, órdenes de servicios y sociedades por acciones simplificadas SAS (Muñoz, 2013).

Una conjunción perversa de las dos tendencias señaladas en la esfera pública y privada se encuentra en la reciente expedición del Decreto 583 de 2016 que acepta todas las formas de tercerización a condición de que cumplan un mínimo de normas laborales. Frente a este cambio, los sectores laborales reclaman que la aprobación de dicha medida, que

6 La Escuela nacional sindical ENS ha elaborado tres documentos que puntualizan los múltiples incumplimientos a los compromisos derivados del TLC E. U. - Colombia para mejorar la protección y el respeto de los derechos laborales, los cuales fueron incluidos en el llamado Plan de Acción Laboral Obama - Santos PAL suscrito en abril de 2011 . 
afecta a los trabajadores y los propósitos de formalización del trabajo, solo se analizó con el gremio empresarial ANDI y no se discutió en la Comisión Permanente de Concertación de Políticas Salariales y Laborales CPCPSL. Por ello, emprenden en el momento una lucha interna sustentando la inconstitucionalidad de la norma, y una lucha externa ante organismos como la OIT al denunciar su carácter regresivo y violatorio de convenios y derechos laborales?

\section{Los temas laborales en los informes de sostenibilidad GRI colombianos}

Las empresas colombianas han adherido a compromisos voluntarios como los del Global Compact de la ONU y adoptado algunas de las metodologías y normas disponibles sobre ciudadanía corporativa, sostenibilidad y metodologías GRI para la presentación de sus informes anuales sobre la base de un conjunto de variables e indicadores estandarizados e internacionalmente aceptados.

A continuación, resumiremos algunas características destacadas de los programas de RSE, en lo referente a condiciones de trabajo, manejo laboral y negociación colectiva, tal como se hallan a partir de la consulta de un conjunto de diez informes que se encuentran disponibles en las páginas web de las firmas.

Estos textos tienen la utilidad de enunciar los principios, metodologías y organizaciones rectoras a los que adhieren las compañías, del mismo modo que describir y cuantificar dentro de parámetros más o menos estandarizados el conjunto de acciones y planes que se desarrollan. Como veremos, las firmas más grandes y avanzadas del país, muchas de ellas con apreciables inversiones en otras naciones, son las que realizan presentaciones más completas y rigurosas en lo técnico.

Escuela Nacional Sindical, Agencia de Información 'Nuevo Decreto 583 sobre tercerización laboral en Colombia: un gran retroceso’ Abril 22 de 2016 
Debe destacarse que cada vez más las empresas incluyen en su informe calificaciones y posicionamientos otorgados por entidades certificadoras y consultoras especializadas en aspectos ambientales, contables, de clima organizacional y manejo laboral. Se trata de un elemento que adquiere creciente importancia en el ámbito sociopolítico, puesto que tales evaluaciones y resultados, como se vio años atrás en el caso de las protestas de trabajadores en los ingenios azucareros, junto con las acciones de RSE, se convierten en referentes y argumentos de las firmas ante los cuestionamientos y debates sociales que llegan a afrontar.

Así mismo, las firmas de mayor tradición y desarrollo, particularmente las asentadas en la región de Antioquia, que fueron pioneras en políticas de bienestar laboral y cierto asistencialismo hacia sus entornos, como las del sector textil, Grupo Corona y Argos, hasta cierto punto mantienen su tendencia a mostrar unos estándares de remuneración y calidad del empleo, y abordan ahora nuevas dimensiones y propósitos como los de equidad de género y equilibrio entre trabajo y familia. Esto último también se percibe en algunas filiales de multinacionales y otras firmas del sector servicios.

El grado de avance que se tenga en estas cuestiones laborales, ahora convertidas en parte de las acciones de RSE, es difícil de valorar, ya que se presentan en muchas ocasiones en simples enunciados de intencionalidad o informaciones difíciles de sopesar, al mismo tiempo que se soslaya o matiza temas problemáticos. Ejemplo de lo anterior, es como al abordar el tema de la negociación colectiva se muestran las minúsculas cifras de los sindicatos independientes que aún subsisten, al mismo tiempo que se muestran las cifras más grandes de los pactos colectivos ${ }^{8}$ que han sido uno de los instrumentos empresariales para debilitar a los

8 Modalidad de negociación reconocida por la legislación colombiana, que hace posible el paralelismo sindical y el debilitamiento de las organizaciones independientes 
primeros. Obviamente es posible y deseable contrastar estas informaciones con los aportes de otras fuentes e introducir dimensiones más amplias de tiempo y otros contextos de actuación del empresariado en el análisis.

\section{Reducida presencia y no reconocimiento de los sindicatos como grupo de interés}

Solo en el caso de un consorcio cementero con plantas en varios países se encontró presencia de voceros obreros, ya que afirman haber establecido un "Modelo de diálogo social con la organización sindical bajo condiciones de respeto, tolerancia, buen trato y comunicación abierta entre las partes” (Argos 2015).

Los demás informes analizados reflejan la inexistencia o muy reducida presencia de las organizaciones en los medios laborales, del mismo modo que se hace visible el desplazamiento de las mismas por el mecanismo del pacto colectivo. En algunos informes los indicadores de comunicación, democracia y participación de los empleados se limita a señalar el mecanismo de elección de los “representantes” en el pacto colectivo o cualquier otra instancia interna que se maneje; se hace referencia a resultados positivos de estudios de clima organizacional contratados (Davivienda 2015, pp. 35, 79, 85).

En el de una conocida fábrica de servilletas y papeles toalla se enuncia el compromiso con los mandatos de la OIT y la disposición a respetar la libertad de asociación e incluyen algunas cifras sobre afiliación a sindicatos: de un total de 4628 en sus cuatro plantas de Colombia y otras en

y con capacidad de convocar paros. En ella se escoge una representación de los empleados, muy limitada en sus posibilidades de negociación y exigencia; altamente tutelada por los patronos y sin ninguna autonomía y capacidad de presión, que en determinados momentos hace peticiones y acuerda con la gerencia mejoras salariales o de otro tipo. 
cuatro países latinoamericanos 311 trabajadores, 5,90\%, están vinculados a un sindicato; 220 de Argentina, 67,28\% del total en ese país, y 91 de Colombia 2,47\% del total (Grupo Familia 2014).

En una firma del grupo empresarial del sector alimentos, con 38.000 empleados, de los cuales 26.000 están en Colombia y 12.000 en plantas del exterior, el $18,6 \%$ de empleados pertenecen a sindicatos y $59,2 \%$ a pactos colectivos. Se afirma haber desarrollado una agenda de trabajo con las organizaciones sindicales en la que se incorporaron temas de interés común; del mismo modo "con líderes de pactos colectivos y representantes de los trabajadores, a fin de promover la participación en el análisis y solución de situaciones laborales de interés común” (Nutresa 2014).

En algunos casos, para exhibir una aceptable democracia interna y canales de participación, se cuantifican diversos mecanismos de información, diálogo, comunicación con los empleados, desde veinte encuentros con el presidente, mensajes del presidente, edición de revistas y otras publicaciones internas, mensajes recogidos en los buzones abiertos a la expresión de los empleados (Éxito 2015).

\section{Políticas laborales de "última generación"}

Se refiere a programas tendientes a mejorar la conciliación vida laboral - vida familiar y la equidad de género. Argos fue la primera empresa colombiana en alcanzar el sello del Sistema de Gestión de Igualdad de Género, Equipares, otorgado por el Programa de Naciones Unidas para el Desarrollo (PNUD) y el Ministerio de Trabajo ${ }^{9}$, como certificación de las condiciones de igualdad de oportunidades para hombres y mujeres (Argos, 2015, pp.12, 25). Este programa ha sido

$9 \quad$ Equipares es un programa de certificación voluntaria que promueven varias entidades, entre ellas el Ministerio de Trabajo, para certificar la buena situación de una empresa respecto a estándares de equidad de género. 
muy divulgado y muestra el esfuerzo por “desgenerizar” los perfiles ocupacionales y los puestos de trabajo, por ejemplo, asignando cincuenta y cinco cargos de conductor de mezcladora a mujeres y otros de oficinistas a hombres.

Un importante consorcio de la industria de alimentos (Nutresa 2014) enuncia objetivos de diversidad e inclusión y avanza en ese propósito con un programa de formación de líderes y equipos de trabajo en la materia; fortaleció un programa de inclusión de personas en situación de discapacidad e incorporó en uno de los negocios la norma de equidad de género "Equipares”. Asimismo, seis compañías del Grupo se certificaron como Empresas Familiarmente Responsables y Organizaciones Saludables, además, obtuvieron la calificación de mejor empresa para trabajar en Colombia en el sector alimentos.

\section{Supervisión de derechos humanos y condiciones laborales a nivel interno y a lo largo de la cadena productiva}

A nivel interno se mencionan capacitaciones, talleres y otras actividades para educar sobre derechos humanos y la redacción de códigos para garantizar su cumplimiento (Familia 2014).

Una gran firma filial de una multinacional de las comunicaciones destaca sus premios y logros en materia de rankings e indicadores de entidades evaluadoras: Premio Andesco al Mejor Desempeño Social, gracias a la gestión de derechos humanos y desempeño social; calificación como una de las veinte más sostenibles y la única del sector de telecomunicaciones, en el estudio de Sustainalytics; varios reconocimientos como uno de los mejores lugares para trabajar en Colombia según el Great Place to Work Institute. Igualmente, subraya su adhesión a los principios de la Norma AA1000 AS del Institute of Social and Ethical Accountability (Telefónica 2014). 
Un ingenio azucarero registra incumplimiento de normas laborales por parte de los proveedores a los que se supervisa (Rio Paila, 2015, p.50). Cementera Argos promueve Cuidémonos, programa que busca afianzar la cultura de seguridad y autocuidado en colaboradores y contratistas y hace auditorías a su cadena productiva para asegurar la no existencia de trabajo infantil (Argos 2015). Igualmente, comunica su postulación al premio del Instituto Great Place To Work, y seguimiento de sus resultados como forma de conocer y mejorar las condiciones laborales (Argos 2015).

\section{Políticas inclusivas y de diversidad}

Un notable consorcio del comercio de gran superficie destaca ser la firma de mayor número de empleados en el país — más de 41.100- y sus esfuerzos por mejorar la participación y distribución equilibrada de géneros; del mismo modo, el incremento en la proporción de empleados ocupados a término indefinido 33.578, frente a 7.563 a término fijo; inclusión laboral de discapacitados, jóvenes en riesgo, víctimas de la violencia, desmovilizados, participación femenina en cargos, capacitaciones, reducción de accidentalidad (Éxito, 2015, 50).

En el caso de una importante fábrica de gaseosas, que cuenta con aproximadamente 10.000 trabajadores, no se presenta ningún tipo de mejora en las políticas laborales y se mencionan como principal aporte a los trabajadores las capacitaciones de recursos humanos: solo $10 \%$ del personal está vinculado a término indefinido y el $80 \%$ son hombres; coexisten convención colectiva y pacto colectivo (Colombiana 2015, p.82).

Telefónica desarrolló programa de "Principios para el empoderamiento de las Mujeres” propuesto por Naciones Unidas (Telefónica 2014). El ranking de "Merco talento Colombia 2015" consideró a Argos la séptima empresa que mejor atrae y retiene su talento humano, ascendiendo dos puestos en la lista en relación a 2014 (Argos 2015). 


\section{Otros programas dirigidos a los empleados}

Promoción del voluntariado y la participación de los empleados en la solución de problemas sociales de comunidades vecinas; capacitaciones, talleres a los proveedores en materia de derechos laborales y respeto a la libertad de asociación (Nutresa 2014). Se incluyen programas y capacitaciones técnicas diversas sobre salud ocupacional, seguridad industrial y bienestar laboral (Argos 2015).

El programa Trabajo con significado de una planta cervecera se esfuerza, mediante entrenamientos y capacitaciones, por motivar, capacitar y dar identidad y sentido de pertenencia a los empleados con sus oficios y puestos (Bavaria, 2014, p.77).

Las anteriores informaciones relativas a acciones de RSE en materia laboral, aunque diversas y poco sistemáticas para evaluar el manejo empresarial, muestran tendencias de interés. En un solo caso se registra entendimiento con organizaciones sindicales, adquieren significación nuevos referentes de la calidad de la gestión empresarial como las certificaciones y sellos de voluntaria aceptación referidos a nuevos y viejos propósitos laborales como la inclusión y equidad de género o la calidad del manejo laboral; para este caso la legitimidad se basa en la buena calificación aportada por una entidad especializada en un proceso en el que no parecen tener presencia los grupos de interés internos.

\section{Los sindicatos colombianos ante la RSE}

Para la exploración de este tópico se entrevistó a directivos de las tres principales confederaciones sindicales (CUT, CGT, CTC) y se examinaron recientes documentos programáticos de esas agremiaciones, después del ejercicio fue clara una marcada ausencia de referencias a las políticas de RSE. En los diálogos, estos voceros manifestaron su crítica y escepticismo frente a tales programas, que son calificados como 
simples y superficiales esfuerzos publicitarios y de imagen ${ }^{10}$; se aportaron numerosos ejemplos sobre la falsedad de logros compendiados en los informes, contradicciones e incongruencias de las firmas en el cumplimiento de los diversos propósitos, conductas fraudulentas y conocidas argucias para reducir impuestos.

La desconfianza de los directivos sindicales sobre los programas de RSE es comprensible, dado el gran número de actuaciones censurables que se registran. Una parte de ellas está asociada al típico patrón de conducta rentístico $^{11}$ de muchas firmas en el escenario nacional, por ejemplo, empresas que planteaban notables compromisos de gobierno corporativo, ética y transparencia realizaron cabildeos y componendas para obtener diferentes tipos de exenciones y privilegios del Estado, o resultaron seriamente implicadas en conocidos casos de cartelización con las que debían ser sus competidoras para elevar los precios a los consumidores por largos períodos (sectores del azúcar, cemento, arroz, cuadernos, pañales y papel higiénico, etcétera).

En otros casos se mencionaron realizaciones de cierta resonancia positiva para la opinión, que resultaron opacadas por acciones censurables en otros frentes de actividad, por ejemplo, perjuicios al medio ambiente, políticas laborales regresivas, actividades corruptas frente a instancias estatales, apoyo a grupos armados ilegales, compra ventajosa de tierras despojadas a campesinos mediante la violencia.

De modo que la percepción de las organizaciones sindicales sobre las acciones 'responsables' de los empresarios o las dirigidas a que sus firmas

La única alusión al tema se halló en Resolución \#5 Empresas trasnacionales y Responsabilidad social empresarial Memorias del encuentro nacional de sindicatos de empresas multinacionales CUT CTC Programa país FNU Bogotá, octubre 29 y 30 de 2012.

11 Para una definición de este rentismo y descripción de diferentes modalidades de ejercicio indebido de presiones corporativas sobre entes reguladores públicos y 
se comporten como 'buenas ciudadanas' es muy negativa; así mismo, no se percibió ninguna expectativa por convertir esas políticas en espacio de interacción constructiva. Sin embargo, respecto a otro elemento relevante en la cuestión laboral actual, como es el planteamiento de la OIT sobre trabajo decente, debe resaltarse que se percibe un buen nivel de conocimiento y disposición entre sectores laborales de todas las tendencias $^{12}$, y aún en algunos espacios empresariales.

En el caso de la Central Unitaria de Trabajadores CUT, hace varios años se conformó un área dedicada a temas relacionados con empresas multinacionales, y se considera a su responsable como el encargado del tema de RSE. Sin embargo, la visión de la RSE no va más allá de una desconfianza y de un rechazo comprensibles dentro de la tradición y el contexto de antagonismo y confrontación que ha caracterizado las relaciones entre sindicatos y sectores empresariales.

Por ello, el plan de acción que se deriva de la mencionada resolución \#5 considera la RSE como un factor a tomar en cuenta, pero no lo aprecia como espacio para intervenir y ganar posiciones. Simplemente plantean la necesidad de establecer redes y nexos con organizaciones de otros países para estructurar una mejor resistencia a las firmas multinacionales, del mismo modo que: "Debatir, profundizar y definir el concepto de «Responsabilidad Social Empresarial» acorde a la realidad y necesidades de los trabajadores para confrontar las normas del Pacto Mundial de la ONU y las directrices establecidas por la Organización de Cooperación y Desarrollo Económico-OCDE”.

conductas tendientes obtener ventajas del Estado e imponer intereses particulares, ver Azuero Zúñiga Francisco 'La búsqueda de rentas: una revisión teórica y sus expresiones en un país emergente’ 2015 (Hasta ahora solo disponle en: https:// www.youtube.com/watch? $\mathrm{v}=$ nU7mivPVhI0)

12 Una ONG importante en ese campo como es la Escuela Nacional Sindical ENS, ha agitado con insistencia el decálogo del trabajo decente, como lo muestran diversos textos promocionales y eventos que ha impulsado. 
Por otra parte, la situación de debilidad, estancamiento numérico ${ }^{13} \mathrm{y}$ atomización de los sindicatos en organizaciones de base y federaciones separadas tampoco propicia que en torno a los programas de RSE se construya un espacio de debate y concertación con los empresarios. Las condiciones de antagonismo y exclusión reinantes en las relaciones laborales, pero también el enclaustramiento de los directivos en las negociaciones, agendas políticas, luchas internas y mantenimiento de posiciones gremiales, dificulta los cambios de orientación al respecto.

\section{Las oportunidades del posconflicto}

La idea de posconflicto como etapa que sigue a la cesación de la confrontación en una sociedad es compleja, polémica y generadora de interrogantes. De modo general y a riesgo de simplificar demasiado, podemos decir que para algunos sectores se trataría de empezar a construir la paz, recuperar la normalidad, estabilizar y recomponer la sociedad. Desde otras perspectivas hay coincidencia con lo anterior, pero se prefiere hablar de posacuerdo, porque consideran que el silencio de las armas no significa que concluya el conflicto si, entre otras cosas, no se reconocen y superan las causas y procesos históricos que condujeron al enfrentamiento armado o se adelanten satisfactorios procesos de verdad, justicia y reparación que impliquen, sin excepción, a todos los partícipes en la guerra.

Desde los estudios de empresa y el sector corporativo se ha analizado la cuestión del conflicto y el posconflicto, los diversos roles que puede tener una organización como afectada, promotora y participe de la violencia, beneficiaria directa o indirecta de la calamidad reinante. En relación con la RSE, se exploran muchas posibilidades y líneas de ac-

La tasa de afiliación más elevada ha sido el 13,4\% del 1965 y para el año 2012 se estimó en 4,2\%, Ver Censos sindicales del Ministerio del Trabajo (1947 - 1984) y ENS Censo sindical (1996 - 2012). 
ción con las que las firmas podrían o deberían contribuir a la resolución del conflicto, pero fundamentalmente a la creación de un nuevo escenario de paz, que, entre otras cosas, redundará en mejores condiciones para la actividad productiva (Prandi y Lozano, 2010).

Una destacada reflexión con la participación del gremio ANDI, sobre las contribuciones posibles del empresariado a la construcción de una paz sostenible, valora experiencias de RSE que se tuvieron entre 2009 y 2013 por parte de firmas comprometidas con la protección de los derechos humanos. Se aprecia también la vinculación a iniciativas internacionales voluntarias con el mismo propósito, la participación en diálogos de paz y apoyo a procesos de reintegración socioeconómica de excombatientes.

Como contribución práctica, se estableció un observatorio de RSE, derechos humanos y construcción de paz para compilar y difundir todas las experiencias útiles en la materia (ANDI, NIR, FIP, 2014).

Aunque se considera muy importante contribuir a la reinserción de excombatientes y el apoyo a víctimas, un estudio sobre modalidades de contribución al posconflicto por parte de firmas multinacionales de origen colombiano señala que solo el $25 \%$ los vincula como empleados, en tanto que la mayoría prefiere ayudarlos a través de Programas de desarrollo y paz y dar donaciones a Fundaciones (Jiménez, Gabriel, 2014 p.87).

Respecto a la sostenibilidad de los programas se destaca el compromiso de los líderes; sin embargo, existe un predominio de situaciones en que los programas descansan sobre la actividad de cargos medios y bajos que trabajan con las comunidades sin que estos esfuerzos de construcción de paz hagan parte del núcleo de la operación empresarial. En cuanto a los montos de financiación hay la impresión de que "tienden a ser muy desiguales entre tipos de empresas y que, en general, tienden a ser bajos, volátiles y vulnerables al desempeño económico anual de las empresas” (Rettberg y Rivas, 2012, p.339). 
En síntesis, de los pocos estudios disponibles y la diversa información de los medios de comunicación, se concluye que la manera como las empresas están contribuyendo a las tareas del posconflicto se fundamenta en los paradigmas de RSE que ya habían adoptado. Se trata de una variada gama de acciones como la simple no implicación para "no hacer daño", fomento de elementos "conectores" — para reducir tensiones sociales-, participación en planes de construcción de la paz, desempeño como negociadores, facilitadores, inversionistas en fondos o proyectos de desarrollo dirigidos a combatientes desmovilizados o las comunidades y grupos de víctimas; asesoría técnica en actividad empresarial y desarrollo productivo.

Sin embargo, estos aportes tangibles no ocultan la ausencia de otros que son importantes en los modelos de RSE y que podrían ser muy decisivos con referencia a los acuerdos de paz, como las políticas de inclusión, transparencia, valoración de los grupos de interés, trabajo decente, diálogo social. Aunque se menciona con frecuencia estos propósitos, es evidente que dentro de las acciones empresariales tienen una menor influencia.

En el terreno de las relaciones laborales, se evidencia la misma tendencia, ya que los empresarios colombianos, en su mayoría permeados por valores paternalistas, parecen satisfechos con sus facultades de manejo autocrático y discrecional de las firmas, sin instancias de acuerdo o compromiso con sectores laborales. Vemos entonces que se da una reproducción de sus ya naturalizadas prácticas de exclusión de cualquier vestigio de representación laboral autónoma y debilitamiento de las pocas que superviven mediante los pactos colectivos y las contrataciones tercerizadas. Los sectores de grandes consorcios, más obligados a fijar posiciones públicas, tienen tanto en sus realizaciones de RSE como en sus certificaciones y posiciones de rankings e indicadores las justificaciones y argumentos unilaterales para reclamar legitimidad ante la sociedad, sin diálogos o acuerdos de alguna significación. 
En la situación actual, la RSE se ha convertido en un elemento orientador importante para las firmas en la definición de sus acciones ante las exigencias del posconflicto. Sin embargo, entre la variedad de paradigmas y programas posibles para diseñar han tenido preeminencia los que implican contribuciones materiales (asesoría, ayuda, recursos); mientras que no se avanza en los que suponen cambiar las relaciones con grupos de interés significativos en este momento histórico como los trabajadores.

Si a esta predominante forma empresarial de contribuir al posconflicto, sin cambios de actitud ante sectores laborales significativos, en lo que sería el ámbito de la RSE interna, se agrega lo descrito antes sobre desconocimiento, escepticismo y desconfianza de los líderes sindicales respecto a las prácticas de RSE, es evidente que se van a desaprovechar las posibilidades de generar cambios de fondo en el comienzo mismo de una etapa que se considera trascendental para el país.

Así mismo, habría una notoria incongruencia frente a las expectativas de participación y diálogo incesantemente expresadas en los dos acuerdos de paz firmados entre el Gobierno y la insurgencia. En tales documentos, diálogo y participación, estructurados en sistemas, instancias, escenarios, y mecanismos, etcétera, están ligados a la construcción de confianza, a la promoción de una cultura de tolerancia, respeto y convivencia; inclusión de comunidades, surgimiento de nuevas fuerzas para enriquecer los debates sociales ${ }^{14}$.

Así pues, la RSE más allá de los estrechos marcos de la dádiva de relaciones públicas de las firmas y de la indiferencia escéptica de los sindicatos, podría ser un mecanismo de entendimiento y transformación. Más aún

14 Ver: 'Acuerdo final para la terminación del conflicto y la construcción de una paz estable y duradera', Agosto 24 de 2016; 'Nuevo acuerdo final de Paz' Noviembre 24 de 2016. 
cuando parece posible concluir la prolongada confrontación y se confía en el comienzo de una etapa nueva y abierta a cambios sociopolíticos positivos. Corresponde a los actores sociales empresarios y trabajadores estructurar nuevas formas de acción para evitar que ocurra una simple mutación de la democracia precaria, la desigualdad y los sistemas de imposición construidos bajo la intimidación y pasividad generada por la guerra.

\section{Conclusión}

A diferencia de lo que se percibe en otros países, de modo especial en las organizaciones obreras de sectores multinacionales, los sindicatos colombianos no se han planteado hasta ahora reclamar y asumir un rol participativo y polémico frente a los discursos y prácticas de RSE de las firmas. No parece visualizarse la posibilidad de convertir este tipo de acciones unilaterales y voluntarias de las empresas en un motivo de diálogo y construcción de mejores escenarios para el entendimiento.

Es obvio que entre firmas y sindicatos ha reinado por mucho tiempo la incomunicación, una mutua y arraigada visión distorsionada del otro y la limitación de las interacciones a la mecánica de la negociación y el pliego petitorio. Se trata de condiciones que impiden concebir por parte de los trabajadores, la posibilidad de incursionar en este contexto de las acciones de RSE.

Es evidente que en este estado de cosas influye una larga historia de hegemonía bipartidista oligárquica, debilidad de sectores sindicales y nuevas corrientes políticas, precario desarrollo de la democracia y las instituciones de ciudadanía y protección social. A lo largo de décadas, dilatados esfuerzos de concertación no han llevado a conformar un marco de entendimientos y auténtico reconocimiento al sector laboral (Celis, Toro y Valero 2014). La fuerza política y negociadora de los sindicatos no sustentada en una capacidad de movilización de los trabajadores o en acuerdos políticos de amplio alcance fracasa intentando 
revertir fuertes y arraigadas tendencias de exclusión y debilitamiento como actor social en el espacio político colombiano.

Cuando se trata de construir una imagen, interactuar restringidamente con sectores de la sociedad o responder por posibles perjuicios ocasionados, los variados instrumentos de la RSE son cada vez más el recurso empleado por las firmas y, al parecer, lo serán en mayor medida en el nuevo contexto socio político del llamado posacuerdo. Sin embargo, hasta ahora estos medios de proyección de las empresas a los grupos de interés son de una sola vía, percibidos como canales para entregar variables apoyos tangibles, mecanismos propagandísticos sin interlocutores activos, cuando no diálogos de convencidos que no sobrepasan niveles organizativos y sociales restringidos.

Es indudable que en la etapa de posconflicto se requerirá una más transparente y democrática interacción entre las firmas y todos los sectores de la sociedad, entre ellos los trabajadores, que genere nuevas posibilidades y espacios de diálogo que construyan verdaderos procesos participativos y de inclusión. En tal escenario, tendrían más sentido los programas de RSE o cualquier otro mecanismo tendiente a superar no solo los impactos adversos del conflicto, sino también los de la globalización neoliberal que, en muchos casos, están íntimamente ligados. 


\section{Referencias}

Akbas, E. (2012). A sociological study of corporate social responsibility: a marxist perspective [Tesis de maestría]. The Graduate School of Social Sciences of Middle East Technical University, Ankara.

Alvarado, A.; Bigné, E. y Currás, R. (2011). Perspectivas teóricas usadas para el estudio de la Responsabilidad social empresarial: una clasificación con base en su racionalidad. Estudios Gerenciales, 17(118), 115-137.

Argos (2011). Reporte integrado.

Argos (2015). Reporte integrado.

Asociación Nacional de Empresarios (Andi), Concejo Internacional de la Economía Sueca (NIR), Fundación Ideas para la Paz (FIP) (2014). ¿Cómo construir la paz desde el sector empresarial?. Bogotá: Autor.

Asocolflores (2009). Florverde ${ }^{\circledR}$ logrando una floricultura competitiva y sostenible, con responsabilidad social.

Banerjee, B. (2011). Corporate Social Responsibility: The Good, the Bad and the Ugly. Critical Sociology, 34(1), 51-79.

Bavaria (2014). Informe de desarrollo sostenible.

Boeddeling, J. (2012). Corporate Social responsibility: a Perspective from Weberian Economic Sociology. Discussion Papers, 22.

Boix, I. (2015). La responsabilidad social empresarial en la acción sindical nacional y transnacional para avanzar hacia un trabajo digno. Madrid: Secretaría de Internacional de CC. OO. IndustriALL Global Union.

Castel, R. (2010). El ascenso de las incertidumbres Trabajo, protecciones, estatuto del individuo. México: FCE.

Celis, J.; Toro, R. y Valero, E. (2014). Sindicalismo colombiano: entre la exclusión del sistema político, el paternalismo y la conflictividad en las relaciones laborales. En Juan Celis (coord.), Reconfiguración de las relaciones entre Estado, sindicatos y partidos en América Latina. Medellín: Clacso, ENS. 
Cerda, C. y Cuevas, H. (2014, febrero). La responsabilidad social empresarial: ¿Una oportunidad para los sindicatos? Sindical. CL.

Davivienda (2015). Sostenibilidad.

Dombois, R. (2011, enero). ¿Regulación internacional del trabajo a partir de los autocompromisos de las empresas transnacionales? Revista CS, 7, 255-276.

Escuela Nacional Sindical (2014). Tres años de incumplimiento del Plan de Acción Laboral Obama-Santos. Medellín: Autor.

Escuela Nacional Sindical (2015). Cuatro años de incumplimiento del Plan de Acción Laboral Obama-Santos. Medellín: Autor.

Escuela Nacional Sindical (2016). Cinco años de incumplimiento del Plan de Acción Laboral Colombia-EE. UU. Cinco años esperando cambios reales. Medellín: Autor.

Éxito (2013). Informe de sostenibilidad.

Éxito (2015). Informe de sostenibilidad.

Fernández-Maldonado, E. (2010). Los trabajadores, sus organizaciones y la responsabilidad social empresarial en el Perú: retos y posibilidades. Derecho PUCP, 64, 281-298.

Greenberg, C. y Hemingway, C. (2007). Empresas felices: la ciencia de la felicidad aplicada a los negocios. Bogotá: Grupo Planeta.

Grupo Familia (2014). Informe de sostenibilidad.

Jiménez, G. (2014, enero-junio). Multinacionales y responsabilidad social empresarial en la construcción de paz en Colombia. Cuadernos de administración, 27(48), 67-96.

Jiménez, J. (2007) La responsabilidad social de las empresas (RSE). Cómo entenderla, cómo afrontarla. Una perspectiva sindical. Albacete: Altaban Ediciones.

Lazin, O. (2007). La globalización se descentraliza libre mercado fundaciones sociedad cívica y gobierno en las regiones del mundo. Guadalajara: Universidad de Guadalajara, UCLA. 
Mitchel, R.; Agle, B. y Wood, D. (1997). Toward a Theory of Stakeholder Identification and Salience: Defining the Principle of who and what Really Counts. Academy of Management Review, 22(4), 853-886.

Muñoz, S. (2013). A dos años del Plan de Acción Laboral: la inspección laboral en Colombia de la crisis al estancamiento. Cultura y trabajo, 89, 7-15.

Murphy, P. (1978). An Evolution: Corporate Social Responsiveness. Business Review, 30, 19-25.

Nutresa Grupo integrado (2013). Informe.

Nutresa Grupo integrado (2014). Informe.

Ormond, J. (2014). Guía informativa de la CES sobre responsabilidad social de las empresas. Bruselas: European Trade Union Confederation.

Partridge, K. (2006). De las palabras a la acción. Manual para la práctica de las relaciones con los grupos de interés. Barcelona: Unep, Stakeholder Research Associates Canada Inc. Accountability.

Postobón (2015). Informe de sostenibilidad Comprometidos con Colombia.

Prandi, M. y Lozano, J. (eds.) (2010). La RSE en contextos de conflicto y postconflicto: de la gestión del riesgo a la creación de valor. Barcelona: Escola de Cultura de Pau (UAB), Instituto de Innovación Social (Esade).

Rauffet, E. y Barrera, E. (2010). Algunos aspectos sobre la responsabilidad social en América Latina: énfasis en la experiencia colombiana y brasileña. En Sébastien A. y Rodrigo M. (eds.), Sociología de la empresa. Del marco histórico a las dinámicas internas. Cali: Eafit, Universidad del Valle.

Raufflet, E. (2012). Responsabilidad social empresarial. México: Pearson Editores.

Rettberg, A. y Rivas, Á. (2012). El sector empresarial en la construcción de paz en Colombia: entre el optimismo y el desencanto. En A. Rettberg (comp.), La construcción de paz en Colombia. Bogotá: Universidad de los Andes, Ceso.

Rio Paila - Castilla (2015). Informe de sostenibilidad y gestión. 
Rossi, C. (2016). Vehiculizando la conciencia del capital: la producción de intelectuales orgánicos. Ponencia en el VIII Congreso Latinoamericano de Estudios del Trabajo. Buenos Aires: Agosto 3-5. Facultad de Ciencias Económicas de la Universidad de Bs. As.

Scott, J. (1990). Los dominados y el arte de la resistencia. México: Ediciones Era.

Telefónica (2014). Informe de sostenibilidad.

Unión Sindical Obrera (USO) (2010). Un buen USO. Guía de buenas prácticas en RSE. Madrid: Fundación Corresponsables.

Valero, E. y Camacho, D. (2006). El lado oscuro en las prácticas de responsabilidad social corporativa del sector floricultor. I., 27, 73-90.

Veloz, E. (Coord.). (2008). ISO 26000 y derechos laborales reflexiones y perspectivas desde las organizaciones sindicales y ciudadanas. México: Fundación Friedrich Ebert.

Vidal, M. (2010). La responsabilidad social de las empresas transnacionales con sede central en España: ¿Neopaternalismo industrial o globalización de derechos? Sociología del Trabajo, 69, 95-119.

Vidal, M. (2012). Las organizaciones sindicales ante la responsabilidad social de las empresas transnacionales en el contexto de la globalización económica. Cuadernos de Relaciones Laborales, 30(2), 431-458. 